\title{
Effects of Hierarchy Vocabulary Exercises on English Vocabulary Acquisition
}

\author{
Lin, Ching-Ying ${ }^{1} \&$ Hsu, Wei Shu ${ }^{1}$ \\ ${ }^{1}$ Department of Applied English, National Pingtung Institute of Commerce, Taiwan \\ Correspondence: Lin, Ching-Ying, Department of Applied English, National Pingtung Institute of Commerce, \\ Taiwan, R.O.C. Tel: 886-8-7238700 Ext: 15100. E-mail: cylin66@npic.edu.tw
}

Received: June 15, 2013 Accepted: July 6, 2013 Online Published: August 15, 2013

doi:10.5539/elt.v6n9p110 URL: http://dx.doi.org/10.5539/elt.v6n9p110

\begin{abstract}
The purpose of the study was to compare the effectiveness of hierarchy vocabulary exercises and copying vocabulary exercises on EFL students' vocabulary acquisition and reading comprehension. Two specific factors were probed: (a) vocabulary gains and retention from different exercises; (b) reading comprehension performance through different exercises. Fifty-six Grade 5 students in Yanpu Elementary School in Taiwan were engaged in either hierarchy vocabulary exercises or copying vocabulary exercises, with sixteen target words. The results revealed that the experimental group receiving hierarchy vocabulary exercises significantly outperformed the control group receiving copying vocabulary exercises on students' performance of vocabulary gains, reading comprehension, as well as short-term and long-term word memory retention. A positive correlation between vocabulary knowledge and reading comprehension was also inspected. It was, therefore, concluded that hierarchy vocabulary exercise was a more effective exercise type for vocabulary acquisition and reading comprehension.
\end{abstract}

Keywords: hierarchy exercise, copying exercise, vocabulary knowledge, word retention, reading comprehension

\section{Introduction}

\subsection{Introduce the Problem}

Vocabulary acquisition may be considered to be the main problem in learning the English language (Amiryousefi, 2011; Green \& Meara, 1995). When teaching a new language, we place great emphasis on the importance of acquiring a useful vocabulary. In the EFL context, there can be no doubt that a limited vocabulary would impede language learning because vocabulary undergirds the four components of language, namely: listening, speaking, reading, and writing (Nam, 2010). It has become a matter of great concern that learners should be given effective instruction and exercises to expand their vocabulary. It is evident that to help learners store and retrieve the target words, language teachers should utilize pedagogical methods effectively (Ramachandran \& Rahim, 2004; Kargozari \& Ghaemi, 2011). Schneider and Evers (2009) mentioned that non-native speakers of English who showed limited English proficiency needed to be given sufficient language processing skills and instructional practice. Moreover, explicit instruction for learning new words can aid learners of a second language to increase their vocabulary and also promote their reading ability (Taylor, Mraz, Nichols, Rickelman, \& Wood, 2009). Vocabulary knowledge is foundational to good reading (Guo \& Roehrig, 2011; Nagy, 1988; Stahl \& Nagy, 2006). Vocabulary exercises are one of the approaches frequently used by English teachers to improve EFL learners' retention of target words (Kan, 2010). Previous research concurred that doing vocabulary exercises after having read the work is outstanding for vocabulary retention (Zimmerman, 1997) and reading comprehension (.Spencer, 2000) However, very little research has been done concerning the effects of different types of exercises. This study fills the gap by comparing two of the vocabulary exercises: hierarchy vocabulary exercises and copying vocabulary exercises.

\subsection{Vocabulary Knowledge in Relation to Reading Comprehension}

A wealth of research has emphasized the positive connection between vocabulary knowledge and reading comprehension (Al Ghafli, 2011; Baba, 2007; Gauthier, 1991; Guo \& Roehrig, 2011; Mezynski, 1983; Nagy \& Herman, 1988; Stahl \& Nagy, 2006; Rashidi \& Khosravi, 2010; Spencer, 2000). It is a fundamental component of language learning that vocabulary knowledge determines learners' comprehension of texts (Rashidi \& 
Khosravi, 2010). To be able to read texts effectively, adequate knowledge of high frequency and supplementary words were taken to be a prerequisite (Rashidi \& Khosravi, 2010).Although the explanation of the relationships between vocabulary knowledge and reading comprehension was seen to be complicated, the strong and positive inter-correlations found among learners' vocabulary size, depth of vocabulary knowledge and reading comprehension implied that vocabulary knowledge directly influenced reading comprehension (Qian, 1998). The complexity of the vocabulary was a valuable factor in predicting reading comprehension. With respect to evaluating reading comprehension and vocabulary knowledge, Spencer (2000) stated that of various measures available, a multiple-choice assessment was the general standardized test format. To measure the depth of learners' word knowledge, a simple test would be to ask learners to distinguish the synonyms or antonyms of the target words. For more in-depth testing, learners could be asked to decide the perfect syntax in sentences by discerning the meanings of the target words. Al Ghafli (2011) stated when the participants' writing ability was not at a high enough level to demonstrate their comprehension; the receptive-skill measure would be used.

\subsection{Short-Term and Long-Term Memory in Vocabulary Learning}

The essential problem in vocabulary learning has to do with memory ( $\mathrm{Gu}, 2003)$. From a psychological perspective, the definition of memory was the capacity for storing, maintaining and recalling daily information (Parle, Singh, \& Vasudevan, 2006). Amiryousefi (2011) also stated that the two essential memory types: short-term and long-term play an influential role in the achievement of vocabulary and grammar. With regard to short-term memory, only a small amount of information can be held in the mental storage capacity so acquisition rate is fast. Unlike short-term memory, long-term memory has an unlimited storage capacity and a slow rate of acquisition. For short-term memory to be transferred to long-term memory, Parle, Singh and Vasudevan (2006) mentioned that regular rehearsals or training was crucial to increasing learners' capacity for retaining information for a long period of time. Sun (2007) stated that exercises with greater exposure to the target words were likely to result in better short-term retention of the words. The fact that word-retention scores between the immediate post-test and the delayed post-test declined in his study was interpreted to mean that the time factor was the main reason for the lack of retention. Over time, words learned by short-term memory could not be retained for long enough to become part of the long-term memory. There would be an ongoing decline in remembering information if learners made no conscious effort to preserve it (Parle, Singh, \& Vasudevan, 2006). On the other hand, according to $\mathrm{Gu}$ (2003), language learning and vocabulary acquisition could be considered to be problem-solving processes at various levels of complexity using memory strategies. These strategies, which comprise person-focused, task-focused and context-focused strategies, should be according to a person-taskcontext-strategy model to ensure a larger capacity for gains in vocabulary. That is, specific strategies should be utilized for larger word memory capacity. Emphasizing strategies to make vocabulary learning less challenging, Nemati (2009) explored the impact of teaching vocabulary by using strategies involving memory. The results showed that the subjects in the experimental group performed better on both short-term and long-term word retention. He interpreted this to mean that learners had engaged in more complex levels of information processing and so had greater long-term recall. Simple rehearsal of words without processing information at a complex level would not boost long-term word retention (Nemati, 2009). According to the depth of processing hypothesis, precise cognitive processing and manipulation of a word would promote its learning (Craik \& Tulving, 1975). Thus, a more complex and richer semantic processing of a word, such as the assessment of a word formula, would lead to greater learning enhancement than a rudimentary process like rote learning (Schmitt \& Schmitt, 1995).

\subsection{Vocabulary Exercises}

Hierarchy vocabulary exercises, developed by Wesche and Paribakht (1994) comprise five categories of mental processing which are required to complete various vocabulary exercises. These categories are: selective attention, recognition, manipulation, interpretation and production. The five categories are hierarchical and are classified according to the learning activities required. Much research has shown the effectiveness of hierarchical vocabulary exercises on vocabulary acquisition (Cheng, 2008; Hsu, 2005; Kan, 2010; Lai, 2009). The first exercise category is selective attention. The widespread application of this type of exercise is first to supply learners with a target word list that serves as the tool to attract the learners' attention. The second exercise category is recognition. The usual application of this type of exercise is asking learners to match the target word with the only correct definition from many word distracters. The third exercise category is manipulation. The general application of this type of exercise is asking learners to construct target words with stems and affixes. The fourth exercise category is interpretation. The common application of this type of exercise is multiple-choice exercises asking learners to guess the word meaning in context. The fifth exercise category is production. The public application of this type of exercise is answering a question by using the target word. Wesche and 
Paribakht (1994) claimed that extensive reading without vocabulary enhancement exercises was insufficient for vocabulary retention and gains. Exercises that drew learners' attention and provided the mental processes required to expand vocabulary and learn new words in depth were indispensable for promoting vocabulary learning (Kargozari \& Ghaemi, 2011). However, previous research has offered mixed perceptions about the effect of copying vocabulary exercises. Thomas and Dieter (1987) stated that copying practice was beneficial for the accuracy and completeness of writing a word. Hummel (2010) confirmed the merits of rote-copying for learning L2 words that copying exercises promoted vocabulary recall in terms of immediate memory. McMaster and $\mathrm{Du}$ (2009) concluded that a copying task was an effective measure of monitoring progress and changes in writing ability of beginner writers. Some divergence regarding copying words has been expressed in other research. Barcroft (2007) mentioned that simple copying did not require the learners to actually produce any language. According to his resource depletion for output hypothesis (Barcroft, 2006), copying vocabulary is a type of output without the means to develop meaning and could drain processing resources. He stated that constrained output yielded negative effects on vocabulary learning because there was no lexical and grammatical activation. Adequate L2 practice for vocabulary learning had to be combined with supplementary techniques, like word association, sorting, and mapping (Oxford, 1990). In Kan's study (2010), copying exercises were less effective for learning vocabulary than hierarchy vocabulary exercises.

\subsection{Research Question}

The purpose of the study was to compare the effectiveness of hierarchy vocabulary exercises and copying vocabulary exercises on EFL learners' vocabulary acquisition and reading comprehension.

Does vocabulary instruction with hierarchy vocabulary exercises result in better gains of target words when compared to copying vocabulary exercises?

Do hierarchy vocabulary exercises work better than copying vocabulary exercises for increasing the English reading comprehension of English learners?

\section{Method}

\subsection{Research Instruments}

Four elements were used to measure learners' performance, in order to meet the demands of the research design. The experiment material, vocabulary exercises, three target-word tests and a reading comprehension test, were presented to the participants in the study.

\subsection{Participants}

There were three Grade 5 elementary school classes of which two were randomly chosen to take part in the study The study was conducted with 56 students of whom 27 were in the experimental group required to do a hierarchy vocabulary exercise and 29 in the control group required to do a copying vocabulary exercise in class after every explicit instruction of target words. Before starting the experiment, two criteria of the homogeneity of the two groups needed to be examined. Based on their English grades from the previous semester and their pretest scores, the levels of participants' English ability $(\mathrm{t}(54)=.470, \mathrm{p}=.640>.05)$ and prior knowledge of the target words ( $\mathrm{t}$ $(54)=.199, \mathrm{p}=.843>.05$ ) were confirmed as equivalent.

\subsection{Data Collection}

In the preparatory stage of the empirical study, it was necessary to select the sixteen target words. All the participants were given the pretest for the first phase. The second phase was the treatment in which two groups were involved in the same vocabulary instruction and received different types of exercise. After the treatment, for the third phase, the immediate post-tests were conducted for forty minutes; this included a vocabulary test for twenty minutes and a reading comprehension test for another twenty minutes. One week after the immediate post-test, the fourth phase was conducted for a twenty-minute delayed post-test. The collection time of data was summarized in Table 1.

Table 1. Timetable of data collection

\begin{tabular}{lll}
\hline Week & Class & Data Collection \\
\hline \multirow{2}{*}{ Week 1 } & Class 1 & Pretest \\
& Class 2 & Target-word instruction and exercise performance \\
Week 2 & Class 1 & Target-word instruction and exercise performance \\
\hline
\end{tabular}




\begin{tabular}{|c|c|c|}
\hline & Class 2 & Target-word instruction and exercise performance \\
\hline \multirow{2}{*}{ Week 3} & Class 1 & Target-word instruction and exercise performance \\
\hline & Class 2 & Target-word instruction and exercise performance \\
\hline \multirow{2}{*}{ Week 4} & Class 1 & Target-word instruction and exercise performance \\
\hline & Class 2 & Target-word instruction and exercise performance \\
\hline \multirow{3}{*}{ Week 5} & Class 1 & Target-word instruction and exercise performance \\
\hline & \multirow{2}{*}{ Class 2} & Immediate post-tests \\
\hline & & (a vocabulary test and a reading comprehension test) \\
\hline \multirow{2}{*}{ Week 6} & Class 1 & (general regular English course) \\
\hline & Class 2 & Delayed post-test \\
\hline
\end{tabular}

\section{Results}

\subsection{Research Question 1}

Does vocabulary instruction with hierarchy vocabulary exercises result in better gains of target words when compared to copying vocabulary exercises?

In order to determine whether the means of the experimental and control groups were significantly different, an independent t-test was administered. For the scores on the immediate vocabulary post-test, the results showed that the mean of the experimental group $(\mathrm{M}=88.81, \mathrm{SD}=17.94)$ was higher than that of the control group $(\mathrm{M}=$ $76.21, \mathrm{SD}=21.40)$. Besides, there was a significant difference between both groups $(\mathrm{t}(54)=2.380, \mathrm{p}=.021$ $<.05$ ). The data was presented in Table 2.

Table 2. The Immediate Vocabulary Post-test of Both Groups $(\mathrm{n}=56)$

\begin{tabular}{lrlllllll}
\hline Groups & $\mathrm{N}$ & Mean & $\mathrm{SD}$ & $\begin{array}{l}\text { Levene's } \\
\text { statistics }\end{array}$ & Sig. & $\mathrm{t}$ & $\mathrm{df}$ & $\mathrm{Sig}$. \\
\hline Experimental & 27 & 88.81 & 17.94 & 3.679 & .060 & 2.380 & 54 & .021 \\
Control & 29 & 76.21 & 21.40 & & & & & \\
\hline
\end{tabular}

Note. ${ }^{*} \mathrm{p}<.05$.

To evaluate the effects of the hierarchy vocabulary exercise on long-term word retention, an independent t-test was conducted to assess whether there was a significant difference between the two groups' means on the delayed vocabulary post-test. The mean of the experimental group $(\mathrm{M}=83.04, \mathrm{SD}=23.71)$ was higher than that of the control group $(\mathrm{M}=67.86, \mathrm{SD}=28.80)$. The results revealed that there was a significant difference between the two groups $((\mathrm{t}(53.229)=2.159, \mathrm{p}=.035<.05)$. The statistical results were presented in Table 3 .

Table 3. The Delayed Vocabulary Post-test of Both Groups $(n=56)$

\begin{tabular}{lllllllll}
\hline Groups & $\mathrm{N}$ & Mean & $\mathrm{SD}$ & $\begin{array}{l}\text { Levene's } \\
\text { statistics }\end{array}$ & Sig. & $\mathrm{t}$ & $\mathrm{df}$ & Sig. \\
\hline Experimental & 27 & 83.04 & 23.71 & 4.315 & .043 & 2.159 & 53.229 & .035 \\
Control & 29 & 67.86 & 28.80 & & & & \\
\hline
\end{tabular}

Note. ${ }^{*} \mathrm{p}<.05$.

\subsection{Research Question 2}

Do hierarchy vocabulary exercises work better than copying vocabulary exercises for increasing the English reading comprehension of English learners? 
In order to evaluate the influence of different types of vocabulary exercises on participants' reading comprehension, an independent t-test was conducted. Next, the relationship between vocabulary achievement and reading comprehension was examined by using correlational analyses. First, the mean of the experimental group $(M=86.67, S D=15.44)$ was higher than that of the control group $(M=60.17, S D=23.13)$. A significant difference was found between the two groups $(\mathrm{t}(49.111)=5.073, \mathrm{p}<.05)$. The effect size was defined as being large $(\mathrm{d}=1.35)$. The data was described in Table 4 .

Table 4. Both Groups' Reading Comprehension Test $(\mathrm{n}=56)$

\begin{tabular}{lllllllll}
\hline Groups & $\mathrm{N}$ & Mean & SD & $\begin{array}{l}\text { Levene's } \\
\text { statistics }\end{array}$ & Sig. & t & df & Sig. \\
\hline Experimental & 27 & 86.67 & 15.44 & 5.673 & .021 & 5.073 & 49.111 & .000 \\
Control & 29 & 60.17 & 23.13 & & & & & \\
\hline
\end{tabular}

Note. $* \mathrm{p}<.05$.

Second, the results indicated positive linear relationships between the scores of the immediate vocabulary test and the reading comprehension test in the experimental group $(r=.608, p=.001)$ and in the control group ( $r$ $=.544, \mathrm{p}=.002)$. The value of correlation coefficient was higher in the experimental group than in the control group. The data was described in Table 5.

Table 5. Correlation Matrix Summary of Both Groups $(n=56)$

\begin{tabular}{lllllll}
\hline & \multicolumn{3}{l}{$\begin{array}{l}\text { Experimental Group } \\
(\mathrm{N}=27)\end{array}$} & & \multicolumn{3}{l}{$\begin{array}{l}\text { Control Group } \\
(\mathrm{N}=29)\end{array}$} \\
\cline { 2 - 7 } & $\mathrm{r}$ & $\mathrm{p}$ & $\mathrm{r}^{2}$ & $\mathrm{r}$ & $\mathrm{p}$ & $\mathrm{r}^{2}$ \\
\hline $\begin{array}{l}\text { Reading Comprehension Test } \\
\text { and } \\
\text { Immediate Vocabulary Test }\end{array}$ & $.608^{*}$ & .001 & .370 & $.544^{*}$ & .002 & .296 \\
\hline
\end{tabular}

Note. $* *$ Correlation is significant at the 0.01 level (2-tailed)

According to the coefficient of determination, the experimental group got an $\mathrm{r} 2$ value of .37 and the control group got an $\mathrm{r} 2$ value of .296. This means that $37 \%$ of the participants in the experimental group and $29.6 \%$ of the participants in the control group would be expected to attain the predicted results. The results were presented in Figure 1.
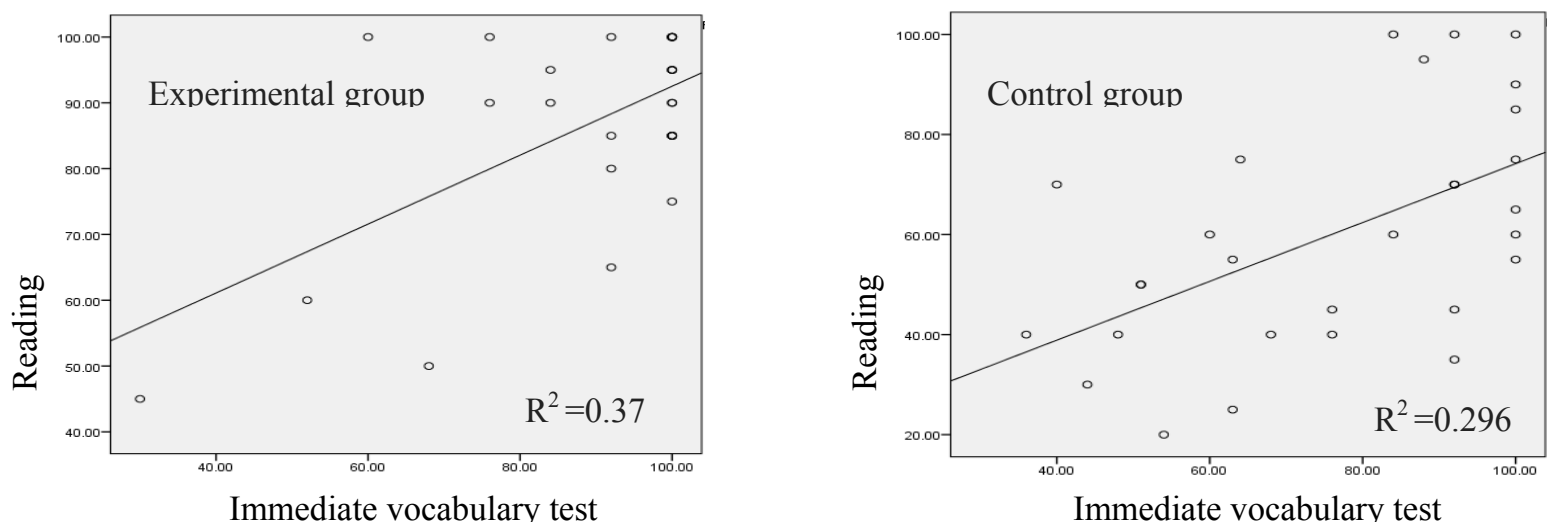

Figure 1. The determination coefficient between the immediate vocabulary test and the reading comprehension test of both groups 
With regard to the relationship between the scores of the delayed vocabulary test and the reading comprehension test, the correlation coefficient was computed again. The results revealed that they were significantly correlated in the experimental group $(\mathrm{r}=.767, \mathrm{p}=.000)$ and in the control group $(\mathrm{r}=.593, \mathrm{p}=.001)$. The $\mathrm{r}$ value was higher in the experimental group than in the control group. The data was shown in Table 6.

Table 6. Correlation Matrix Summary of Both Groups $(n=56)$

\begin{tabular}{lcccccc}
\hline & \multicolumn{3}{c}{$\begin{array}{l}\text { Experimental Group } \\
\text { (N=27) }\end{array}$} & \multicolumn{3}{l}{$\begin{array}{l}\text { Control Group } \\
(\mathrm{N}=29)\end{array}$} \\
\cline { 2 - 7 } & $\mathrm{r}$ & $\mathrm{p}$ & $\mathrm{r}^{2}$ & $\mathrm{r}$ & $\mathrm{p}$ & $\mathrm{r}^{2}$ \\
\hline $\begin{array}{l}\text { Reading Comprehension Test } \\
\text { and }\end{array}$ & $.767^{*}$ & .000 & .589 & $.593 *$ & .001 & .352 \\
$\begin{array}{l}\text { Delayed Vocabulary Test } \\
\text { **Correlation is significant at the } 0.01 \text { level (2-tailed) }\end{array}$ & & & & & \\
\hline
\end{tabular}

As for the coefficient of determination, the experimental group obtained an $\mathrm{r} 2$ value of .589 and the control group obtained an $\mathrm{r} 2$ value of .352. That is, $58.9 \%$ of the participants in the experimental group and $35.2 \%$ of the participants in the control group would be expected to obtain the predicted results. The results were presented in Figure 2.
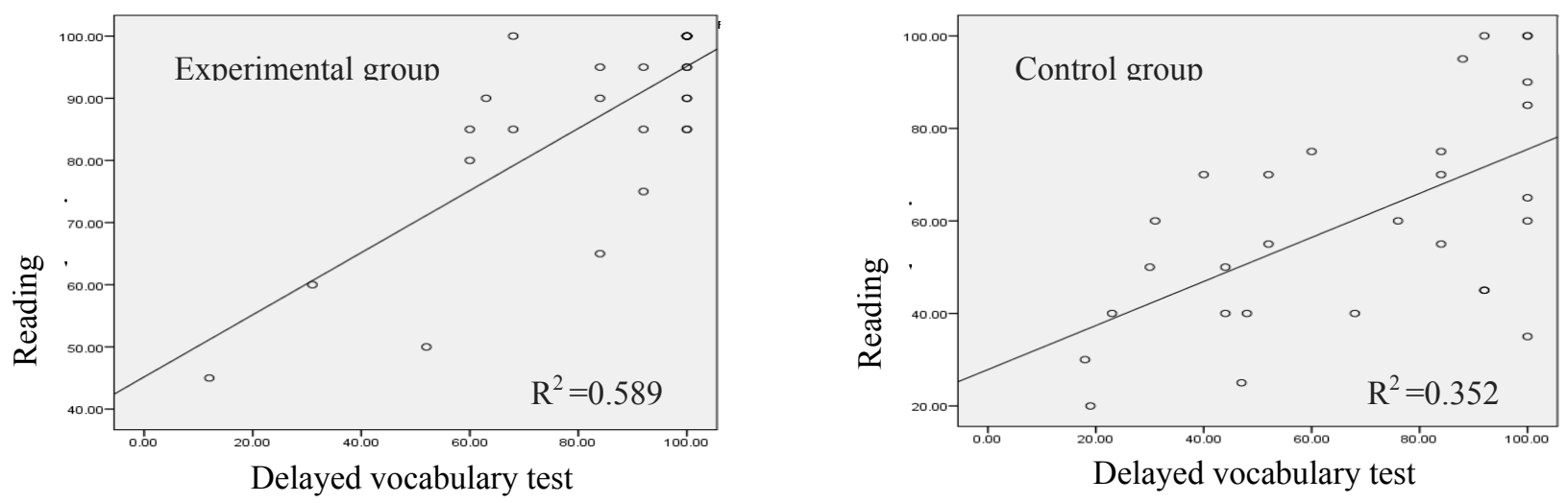

Figure 2 . The determination coefficient between the delayed vocabulary test and the reading comprehension test of both groups

\section{Discussion}

\subsection{Effects of Hierarchy Vocabulary Exercises on Word Gains in Terms of Short-Term Memory}

This research question aimed to assess the effect of two types of vocabulary exercises on English vocabulary acquisition and retention. The results found that there was a significant mean difference between the experimental group $(\mathrm{M}=88.81, \mathrm{SD}=17.94)$ and the control group $(\mathrm{M}=76.21, \mathrm{SD}=21.40)$ on the immediate vocabulary posttests. That is, the statistical significance of the hierarchical vocabulary exercises on word retention and gains was investigated. With the hierarchy vocabulary exercises, learners experienced target words through five mental operations that processed vocabulary knowledge from a simple stage to a complicated stage. This type of exercise was designed to help learners notice, discern, construct, contextualize, and generate target words stage by stage. Such mental operations furnished learners with tools to comprehend words (Wesche \& Paribakht, 1994). For the experimental group, learners get more diverse practice with words. In the control group, learners just duplicate the words, phrases, and example sentences without deeper and more detailed thinking. Therefore, the better performance in the experimental group was consistent with the argument that more mental processing and manipulation would contribute to vocabulary learning (Craik \& Tulving, 1975). On the other hand, the poorer retention scores in the control group were probably due to the fact that the type of exercise used was a form of rote repetition and so resulted in less word-learning effectiveness. The finding reflected the 
account of Schmitt and Schmitt (1995) that vocabulary acquisition was enhanced by engaging deeper mental processes when learning words than through a rudimentary process. As indicated in the results, hierarchy vocabulary exercises significantly affected how well learners did on the vocabulary test when compared to copying vocabulary exercises. The participants had better immediate word retention when the words were practiced with hierarchy vocabulary exercises. These results accorded with the findings of Cheng (2008), Hsu (2005), Kan (2010), Lai (2009), and Wesche and Paribakht (1994) who found that better word gains were demonstrated when a hierarchical vocabulary exercise was administered.

\subsection{Effects of Hierarchy Vocabulary Exercises on Word Gains in Terms of Long-Term Memory}

The purpose of this research question was also to detect whether the experimental group had better performance than the control group in terms of long-term memory. According to the data computed from the delayed vocabulary post-test, the mean scores of the control group $(\mathrm{M}=67.86)$ was much lower than those of the experimental group $(M=83.04)$. The results revealed that the hierarchical vocabulary exercise had a significant effect on long-term memory and word retention $(\mathrm{t}(53.229)=2.159, \mathrm{p}=.035<.05)$. In other words, hierarchy vocabulary exercises were more effective in promoting long-term word retention than copying vocabulary exercises. In the current study, hierarchy vocabulary exercises based on Wesche and Paribakht's (1994) five categories possessed the requirements of different mental-processing levels that were indispensable for language acquisition. Lai (2009) mentioned that when learners implemented a hierarchy of vocabulary exercises, they were involved in elaborate mental processing of input and output. On the contrary, copying vocabulary exercises provided drills in reiterating and writing material designed in advance. During the process, what learners needed to do was to copy down the material without attempting to solve any language problems; sometimes without actually thinking at all. When doing copying vocabulary exercises, learners did not engage in mental operations at complex levels. According to Nemati (2009), learners had greater long-term recall of the target words because they engaged in in-depth information processing. In contrast, primary and simple rehearsal with no in-depth processing of information would not enhance learners' long-term retention of words (Nemati, 2009). Therefore, the hierarchy vocabulary exercises had a greater effect on learner's acquisition of words because they encourage complicated engagement with the words and help word retention for a longer period. Another finding to be observed was that test scores from the immediate vocabulary post-test and the delayed vocabulary post-test declined in both groups. In the experimental group, the mean scores decreased from 88.81 to 83.04 and in the control group the mean scores decreased from 76.21 to 67.86 . The immediate test mean was considerably higher than the delayed test mean. It was possible that learners forgot some of the words that they had learned during the testing procedure. These learned words could not be retained for a week. According to Sun (2007) and Pimsleur (1976), one possible reason for this was that the time lapse resulted in a fading of the learners' word retention. Another possible reason was that vocabulary practice was suspended for a week because learners were not notified of the delayed post-test in advance. Thus, learners did not retain the memory of the words over this period of time. This was in agreement with the findings that regular rehearsals or training was crucial for the transfer of short-term memory to long-term memory (Hashemzadeh, 2012; Parle, Singh \& Vasudevan, 2006). On the other hand, the difference between the two test means in the experimental group (5.77) was less than that of the control group (8.35). That is, as time passed, learners who had received the hierarchical vocabulary exercises would have a better memory of the target words. This finding was also consistent with the positive effect of hierarchical vocabulary exercises.

\subsection{Effects of Hierarchy Vocabulary Exercises on Reading Comprehension}

This research question probed how the two types of exercise influenced learners' reading comprehension and how vocabulary knowledge and reading comprehension were correlated. There was a significant effect of vocabulary exercise type on participants' reading comprehension performance, with the experimental group receiving higher scores than the control group $(\mathrm{t}(49.111)=5.073, \mathrm{p}<.001)$. In other words, for English reading comprehension, hierarchy vocabulary exercises were more effective than copying vocabulary exercises, indicating that the type of vocabulary exercise was a significant factor in learners' reading comprehension. Moreover, as the results showed, the effect size $(d=1.35)$ was described as being large, revealing that the hierarchy vocabulary exercises were strongly effective for the growth of learners' reading comprehension.

Based on the five categories proposed by Wesche and Paribakht (1994), learners in the experimental group processed their language learning in hierarchy steps. From the noticing stage to the comprehension stage, learners established a consistent form-meaning connection, implying further mental and cognitive processing had taken place. Especially in the third to fifth categories, learners would involve themselves in morphology, syntax, semantics, grammar and contextual associations of target word knowledge, signifying more actual operating of word usage. By applying hierarchy vocabulary exercises, learners could receive and produce more 
comprehensible input and output of a word than would be possible from the rote repetition demanded in copying vocabulary exercises. Vocabulary exercises that have variety and demand mental processes would facilitate the acquisition and retention of word knowledge (Lai, 2009). The findings were consistent with those of Craik and Tulving (1975) that processing and manipulating a word mentally and in detail would help with its learning. Conversely, the rote repetition of a word, unlike processing a word deeply, would have a less positive effect on language learning (Schmitt \& Schmitt, 1995).

Next, in the immediate and delayed vocabulary tests, the scores of the vocabulary tests were correlated with the scores of the reading comprehension test in both groups. The results showed that there was a positive linear relationship between word knowledge and reading comprehension which was congruent with much previous research (Al Ghafli, 2011; Baba, 2007; Gauthier, 1991; Mezynski, 1983; Nagy \& Herman, 1988; Stahl \& Nagy, 2006; Spencer, 2000). The positive nature of the relationship suggested that learners who had higher vocabulary test scores tended to get higher scores on the reading comprehension test. In other words, the better the learners' vocabulary performance, the better the learners' reading comprehension, echoing Spencer's (2000) assertion that increased word acquisition contributed to enhanced reading comprehension. As previously mentioned, the findings also showed a stronger relationship between the two test scores in the experimental group than in the control group. Such findings could be interpreted to mean that it is possible to predict the reading comprehension test scores based on the vocabulary test scores in the experimental group than in the control group. Between the immediate vocabulary test and the reading comprehension test, $37 \%$ of the learners in the experimental group and $29.6 \%$ of the learners in the control group were likely to fulfill the prediction. Moreover, according to the results of the delayed vocabulary test and the reading comprehension test, the results of $58.9 \%$ of the learners in the experimental group and $35.2 \%$ of the learners in control group could probably to be predicted.

\section{Discussion}

The immediate vocabulary test was executed to examine whether the means of the experimental and control groups were significantly different at a selected probability level $(\alpha<.05)$ after hierarchy vocabulary exercises instruction. The Cronbach's alpha value of .831 confirmed the reliability and internal consistency of the test. An independent t-test using vocabulary exercise types as the independent variable was administered to assess learners' word acquisition. The results indicated that the performance of each group differs significantly. The difference showed that the participants who received hierarchy vocabulary exercises after formal word instruction perform significantly better than those who received copying vocabulary exercises in terms of short-term memory. For short-term memory, hierarchy vocabulary exercises were more beneficial.

Regarding learners' differential recall in the delayed post-test, an interval of one week was selected to measure learners' long-term memory capacity. To ensure fairness, none of the participants was informed about the final test. With no additional practice for the retention test, the information that was retained in the memory would be mainly from the instruction procedure. From the comparative data of both groups, it was revealed that the experimental group showed better word recall than the control group. It could be concluded that hierarchy vocabulary exercises have an influential role in learners' vocabulary retention in terms of long-term memory. Due to the greater depth of cognitive operations, vocabulary knowledge is stored for a longer period of time (Craik \& Tulying, 1975; Nemati, 2009; Schmitt \& Scmitt, 1995).

To examine the benefits of the vocabulary exercises on learners' English reading comprehension, a multiple-choice assessment was regarded as the general standardized test format by the reading comprehension test (Spencer, 2000). In the same class of week five, the immediate vocabulary test was conducted and was followed by the reading comprehension test. The results from independent t-tests showed that the experimental group performed significantly better in the reading comprehension test than the control group. Thus, for English reading comprehension, the learners who received the hierarchy vocabulary exercises significantly outperformed the learners who received the copying vocabulary exercises. The researcher computed a correlation matrix which included two variables: vocabulary test scores and reading comprehension test scores, for both groups. No matter whether it was the data from the immediate or the delayed post-tests that were analyzed, there was a positive linear relationship between vocabulary knowledge and reading comprehension. Moreover, according to the results of the delayed vocabulary test and the immediate reading comprehension test, one finding was worthy to be noticed. The highly correlated relationship between them indicated that the higher the learners' reading comprehension test scores, the better the learners' long-term vocabulary memory. The finding revealed that the positive effects of hierarchy vocabulary exercises on comprehending a text could increase the recall of target words, supporting the validity of the results of Research Question 1. As previously mentioned, the hierarchy vocabulary exercises, based on five categories proposed by Wesche and Paribakht (1994), allow learners to process vocabulary knowledge at a more complex level. Vocabulary exercises with requiring complex mental 
operations could promote learners' vocabulary retention and enhance their reading comprehension.

\section{References}

Al Ghafli, M. H. (2011). The effect of mediated glosses on vocabulary retention and reading comprehension with English language learners in Saudi Arabia. Dissertation Abstracts International, 72(9), A. (UMI No. 3458207)

Amiryousefi, M. (2011). Mnemonic instruction: a way to boost vocabulary learning and recall. Journal of Language Teaching and Research, 2(1), 178-182. http://dx.doi.org/10.4304/jltr.2.1.178-182

Barcroft, J. (2006). Can writing a new word detract from learning it? More negative effects of forced output during vocabulary learning. Second Language Research, 22(4), 487-497. http://dx.doi.org/10.1191/0267658306sr276oa

Barcroft, J. (2007). Effects of word and fragment writing during L2 vocabulary learning. Foreign Language Annals, 40(4), 713-726. http://dx.doi.org/10.1111/j.1944-9720.2007.tb02889.x

Baba, K. (2007). Dimensions of lexical proficiency in writing summaries for an English as a foreign language test. Dissertation Abstracts International, 68(6), 2288A. (UMI No. NR27917)

Cheng, Y. L. (2008). Enhancing Noun Acquisition through Reading: the Impact of a Hierarchy of Vocabulary Exercise on Young Learners of Different English Proficiency in an EFL Context. Unpublished master's thesis, National Taipei University of Education, Taipei, Taiwan.

Craik, F. I. M., \& Tulving E. (1975). Depth of processing and retention of words in episodic memory. Journal of Experimental Psychology, 104(3), 268-294. http://dx.doi.org/10.1037/0096-3445.104.3.268

Green, D., \& Meara, P. (1995). Computer-Assisted Language Learning. Guest Editorial, 8(2/3), 97-101.

Gu, P. Y. (2003). Vocabulary learning in a second language: person, task, context and strategies. TESL-EJ, 7(2), $1-28$.

Gauthier, L. R. (1991). The effects of vocabulary gain upon instructional reading level. Reading Improvement, 28 , 195-202.

Guo, Y., \& Roehrig, A. D. (2011). Roles of general versus second language (L2) knowledge in L2 reading comprehension. Reading in a Foreign Language, 23(1), $42-64$.

Hashemzzadeh, M. (2012). The effect of exercise types on EFL learners' vocabulary retention. Theory and Practice in Language Studies, 2(8), 1716-1727. http://dx.doi.org/10.4304/tpls.2.8.1716-1727

Hummel, K. M. (2010). Translation and short-term L2 vocabulary retention: Hindrance or help? Language Teaching Research, 14(1), 61-74. http://dx.doi.org/10.1177/1362168809346497

Hsu, W. S. (2005). The Effects of Vocabulary Enhancement Instruction and Reading Only Instruction on EFL Senior High School Students' Vocabulary Acquisition in the Context of a Reading Program. Unpublished master's thesis, National Cheng Kung University, Tainan, Taiwan.

Kan, H. C. (2010). The Effects of After-Instruction Vocabulary Exercises on Taiwanese Young Learners' Vocabulary Acquisition: Hierarchy Vocabulary Exercises vs. Copying Exercises. Unpublished master's thesis, National Chengchi University, Taipei, Taiwan.

Kargozari, H., \& Ghaemi, H. (2011). A reappraisal perspective on written tasks types and vocabulary acquisition and retention of EFL learners. World Applied Sciences Journal, 12(10), 1653-1661.

Lai, Y. H. (2009). The Effect of Post-Reading Vocabulary-Enhancing Activities on EFL Vocabulary Acquisition and Retention. Unpublished master's thesis, National Taiwan Normal University, Taipei, Taiwan.

Mezynski, K. (1983). Issues concerning the acquisition of knowledge: effects of vocabulary training on reading

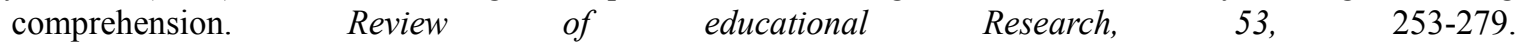
http://dx.doi.org/10.3102/00346543053002253

McMaster, K. L., \& Du, X. (2009). Technical features of curriculum-based measures for beginning writers. Journal of Learning Disabilities, 42(1), 41-60. http://dx.doi.org/10.1177/0022219408326212

Nam, J. (2010). Linking research and practice: effective strategies for teaching vocabulary in the ESL classroom. TESL Canada Journal, 28(1), 127-135.

Nagy, W. E., \& Herman, P. A. (1988). Teaching vocabulary to improve reading comprehension. Newark, DE: International Reading Association. 
Nemati, A. (2009). Memory vocabulary learning strategies and long-term retention. International Journal of Vocational and Technical Education, 1(2), 14-24.

Oxford, R. (1990). Language learning strategies: what every teacher should know. New York: Newbury House.

Pimsleur, P. (1976). A memory schedule. Modern Language, 51(2), 73-75. http://dx.doi.org/10.1111/j.1540-4781.1967.tb06700.x

Parle, M., Singh, N., \& Vasudevan, M. (2006). Regular rehearsal helps in consolidation of long term memory. Journal of Sports Science and Medicine, 5, 80-88.

Qian, D. D. (1998). Depth of vocabulary knowledge: assessing its role in adults reading comprehension in English as a second language. Dissertation Abstracts International, 59(12), 4384A. (UMI No. NQ33914)

Ramachandran, S. D., \& Rahim, H. A. (2004). Linking meaning recall and retention: the impact of the translation method on elementary level learners' vocabulary learning. Language Teaching and Research, 35(2), $161-178$

Rashidi, N., \& Khosravi, N. (2010). Assessing the role of depth and breadth of vocabulary knowledge in reading comprehension of Iranian EFL learners. Journal of Pan-Pacific Association of Applied Linguistics, 14(1), 81-108.

Schneider, E., \& Evers, T. (2009). Linguistic intervention techniques for at-risk English language learners. Foreign Language Annals, 42(1), 55-76. http://dx.doi.org/10.1111/j.1944-9720.2009.01008.x

Sun, J. T. (2007). A Comparative Study of the Effects of Original Sentence Writing and Multiple Choice on Junior High School Students' Vocabulary Retention. Unpublished master's thesis, National Kaohsiung Normal University, Kaohsiung, Taiwan.

Spencer, J. P. (2000). Vocabulary acquisition: a comparison of three methods of teaching vocabulary. Master Abstracts International, 40(1), 84. (UMI No. 1405187)

Stahl, S. A., \& Nagy, W. E. (2006). Teaching word meanings. Mahwah, N. J: Lawrence Erlbaum Associates.

Schmitt, N., \& Schmitt, D. (1995). Vocabulary notebooks: Theoretical understanding and practical suggestions. ELT J, 49(2), 133-142. http://dx.doi.org/10.1093/elt/49.2.133

Taylor, D. B., Mraz, M., Nichols, W. D., Rickelman, R. J., \& Wood, K. D. (2009). Using explicit instruction to promote vocabulary learning for struggling readers. Reading \& Writing Quarterly, 25(2/3), 205-220. http://dx.doi.org/10.1080/10573560802683663

Thomas, M. H., \& Dieter, J. N. (1987). The positive effects of writing practice on integration of foreign words in memory. Journal of Educational Psychology, 79(3), 249-253. http://dx.doi.org/10.1037/0022-0663.79.3.249

Wesche, M., \& Paribakht, T. S. (1994). Enhancing vocabulary acquisition through readings: A hierarchy of text-related exercise types. Paper presented at the Annual Meeting of the American Association for Applied Linguistics.

Zimmerman, C. (1997). Do reading and interactive vocabulary instruction make a difference? An empirical study. TESOL Quarterly, 31, 121-140. http://dx.doi.org/10.2307/3587978

\section{Copyrights}

Copyright for this article is retained by the author(s), with first publication rights granted to the journal.

This is an open-access article distributed under the terms and conditions of the Creative Commons Attribution license (http://creativecommons.org/licenses/by/3.0/). 